\title{
A Study on the Relationship between Urban Landscape Design and Cultural Influence
}

\author{
Huang Liang \\ Department of Art Design, Chongqing Aerospace Polytechnic, Chongqing, China
}

Keywords: City; Landscape Design; Cultural Influence

\begin{abstract}
With the development of economy and society, urbanization has been accelerating in China. In the process of urban development, the design and setting of urban landscape not only affect the appearance of the city but also has a significant impact on the display of urban cultural tension. This paper briefly discusses the relationship between urban landscape design and urban cultural influence and gives the idea about urban landscape creation in line with the future urban development trend.
\end{abstract}

With the continuous development of China's economy and society, the current urbanization process has obviously accelerated compared with previous years. An indispensable part of urbanization is the construction and vigorous development of the city. At the beginning of reform and opening up, China paid more attention to the overall planning of the city and the landscape design of the city in promoting urbanization. Nowadays, as more than 30 years have passed, relatively complete planning, design, and construction ideas have been formed in China's urban construction in many aspects. Among them, it is particularly worth pointing out that the urban landscape design has become the primary consideration in the urban planning for many cities.

However, China's urbanization system is not perfect. For example, in terms of the influence of urban culture, although many cities have taken this factor into account in landscape design and urban construction, cultural influence is a more ambiguous concept. In addition, China do not have much experience in this process during the planning and construction, thus the planning and design of the city is separated from landscape design and the cultural heritage of the city itself. It is difficult for the two to form an organic whole and achieve synergy.

It is an unavoidable reality in urban planning and construction in the new era as how to fully consider cultural factors in urban landscape design, let the city's cultural influence be expressed through urban landscape design, and highlight it through landscape design.

At present, there are two kinds of thinking in the field of urban landscape design. One is that it is only necessary to do a good job of designing and constructing a single landscape in urban landscape design, and there is no need to associate the cultural influence of the city with a single landscape. Otherwise, it is easy to constrain the idea of urban landscape design, resulting in a dull design style of the entire city. Another idea is that the urban landscape design ultimately serves the development of the overall layout of the city. Therefore, the urban landscape design should fully consider the many elements of urban development, especially the cultural influence. In fact, these two kinds of thinking are one-sided. First of all, the influence of urban cultural influence is diverse. As long as the design needs and cultural influences are fully considered, even a single design idea can present a variety of works. Secondly, the cultural influence of the city is composed of all the landscape design of the city. Therefore, even if the single work has nothing to do with this theme, it does not pose a challenge and threat to the overall cultural layout of the city. Any unilateral negation and fragmentation of urban landscape design and urban cultural influence are not correct.

\section{Cultural Factors to be Considered in Urban Landscape Design}

Urban landscape design is receiving more and more attention in toda's society. This concern is not limited to the official level, and many residents living in the city are also very concerned about this issue. Urban landscape design can beautify the environment and improve people's life standard. 
However, urban landscape design is a comprehensive discipline. Nowadays, in the context of the great development of the city, there are constantly improving requirements for urban and people for urban landscape design. Many of these requirements are intrinsic, that is, the urban landscape design and construction are examined from a cultural perspective.

The cultural factors that need to be considered in urban landscape design mainly include historical and cultural factors, natural law factors, local cultural factors, and national cultural factors.

\section{Historical and cultural factors}

The results of urban landscape design should ultimately be applied to urban construction. Therefore, the historical and cultural factors of the city are always inseparable from the urban landscape design. From a certain perspective, landscape design is an art itself and an art of survival. The landscape design and construction of the city solves the problem of the life of the urban population. To put it simply, the cultural differences caused by historical reasons in the north and south of China put forward different standards for urban landscape design. For example, in the historical and cultural beliefs of the North, they advocate the round heaven and square earth. This is often seen in many urban architecture and landscape designs in the North. For example, the Forbidden City and Beijing City in Beijing are the standard symbols of this historical and cultural belief. The grand and magnificent Forbidden City, the top floor of the building is constructed in a circular shape, and the walls are square. From the cultural point of view, this design contains the design concept of atmosphere and rules in the northern cultural beliefs. Today, there are many high-rise buildings and landscape designs in the northern cities. Under the appearance of feasting and glitz, all reflect the ancient Chinese cultural heritage. Whether it is the downtown area or the residential area outside the city, the left and right or front and rear symmetrical design ideas are deeply engraved in the marrow of the city. However, the softness of the water system in the south has made the urban landscape design have a different appearance. The long history of the Yangtze River system has given birth to the unique tenderness of the Southerners. The water culture landscape has always been a shining pearl in China's urban landscape design. If the landscape design of the southern city is separated from the water, it is like the body peeling off the soul. This will never give people a sense of joy and reunion.

\section{Natural law factor}

Some people must wonder why the natural law factors are placed within the scope of urban cultural factors. In fact, although natural conditions and natural laws are not cultural factors, natural laws and natural conditions are an important basis for the formation of culture. For example, the differences in design ideas between the North and the South, which have just been mentioned, cannot be separated from the constraints of natural factors and natural laws. Natural law factors play an important role in the design of urban landscapes. Although they are all in the north, the development track of urban construction in Inner Mongolia, Shaanxi, and Shanxi is not the same. Although the yurt is the simplest form of human settlements, it is very rare in Shaanxi and Shanxi. The reason is inextricably linked with the natural conditions and natural laws of Inner Mongolia. Another example is Sichuan and Guangdong in the south. They also have many differences in the design and layout of urban landscapes. Guangdong's urban landscape design is more exquisite than Sichuan, and Sichuan's urban landscape design is better than fine and delicate.

\section{Local cultural factors}

Urban landscape design has a very long history in China, but in the modern era, the West has made remarkable achievements in urban landscape design. In the 1980s, after China's reform and opening up, due to the impact of foreign culture, many people in China were totally influenced by Westernization in their thinking. In their view, the moon abroad is more round than the domestic 
one. Some urban landscape design professionals began to be inclined to the West in design thinking, allowing local culture to give way to Western culture. In their view, China's local culture has no merit. Even when many scholars talked about this issue, they simply attributed the traditional urban landscape design of China to Feng Shui, which is associated with feudal superstition. This problem was more prominent in the 1990s. We can now see in many cities that the urban landscape planned and constructed in the 1990s is basically the logic and standard of Westernization, whether it is from the layout or the selection of materials.

We can't deny that the West started early in urbanization and its experience is more profound than ours. We are not saying that we must exclude foreign cultures. Under the conditions of globalization, no cultural tradition can exist in isolation. However, we should adopt a fair and objective attitude towards foreign culture. Secondly, we must also correct some people's arrogance, narrow and conservative nationalist ideas, and adopt an inclusive attitude to look at the diversity of the world and face the problems we have. We must learn a variety of new ideas with great enthusiasm, new thoughts, thinking in introduction and imitation, and innovation in introduction and imitation.

The pace of globalization is unstoppable, and we should pay more attention to promoting local culture while accepting adoption. Urban landscape design is a process in which human beings carry out their spiritual will in social life. Therefore, urban landscape design has always been inseparable from the spiritual world of mankind, which is the cultural world. We must be good at exploring the bright spots in our local culture and be good at using the essence of local culture.

\section{Ethnical and cultural factors}

A good urban landscape design is inevitably closely related to national cultural factors. In the history of China's cultural development, Taoism, Confucianism, or Buddhism culture have left a deep mark on history. To a certain extent, they have even become representative symbols of Chinese culture. Of course, our national cultural factors have many elements, and they all influence Chinese national culture with their own cultural characteristics. The urban landscape design based on the development of these national cultural genes is undoubtedly deeply branded as a national culture. Many designers are constantly exploring the treasures of national culture for their own use, and displaying their profound national cultural connotations with their own works, so that the people can think from the heart in the process of appreciating the landscape. Let the people feel the cultural characteristics and cultural beliefs of the ancient people from the heart, and let the urban landscape sublimate into the fulcrum of strengthening national consciousness.

\section{Urban Landscape Design Development Trend and Urban Cultural Grade Construction}

Strengthening the construction of urban taste has become a key link in the future urban construction. The current era is an era in which emphasis is placed on cultural strategy development. The cultural development strategy has become the first consideration and layout in the development of the country and urban development. The cultural taste of a city, in a broad sense, refers to the urban state of a city's cultural character, cultural status, and the resulting cultural influence. In a narrow sense, cultural taste refers to the cultural spirit and style formed by the cultural factors carried by a city. At present, China's urban construction has reached a high standard in hardware investment, but the process of urban modernization is the process of comprehensive development of economic and political culture. The construction of urban cultural taste plays an important role in accelerating urban modernization.

A city can be divided from different angles such as economy, society, history, and ecology. But a combination of many factors constitutes a complete urban ecology. Advanced and developed education, culture, science and technology, and health systems are important features of a modern metropolis. In recent years, many cities have realized the important position and role of cultural taste construction in urban development strategies, and have formulated a series of measures to promote urban cultural construction. Major cities such as Beijing, Shanghai and Guangzhou have 
listed cultural development as one of the top considerations for future urban planning. Among them, Beijing proposed to make full use of its location advantages, constantly work hard on cultural resources and human resources, and vigorously develop pillar culture industries, so that Beijing's urban construction and planning will develop in a direction that is conducive to the development of Beijing's cultural characteristics. It can be predicted that in the near future, urban landscape design will inevitably become closer to the cultural orientation of the city. The creative introduction of cultural factors into urban landscape design is a realistic issue that needs to be solved for every urban landscape design professional.

\section{Conclusion}

Urban landscape design and cultural influence complement each other and promote and support each other. We must grasp the pulse of the development of the times. In the urban landscape design, we must fully consider the cultural appeal of urban construction and development, so that the urban landscape design can become a beautiful city business card as well as a symbol of urban cultural temperament.

\section{References}

[1] Zhu Weidong. Application of Chinese Traditional Elements in Modern Garden Landscape Design [J]. Modern Landscape, 2011(07)

[2] Xu Weiwei. On the Performance of National Culture in Landscape Design [J]. Modern Landscape, 2013(06)

[3] Tan Wenyong, Chen Jincai. Application of Traditional Culture in Modern Garden Design [J]. Modern Agricultural Technology, 2015(18)

[4] Xiao Bin. Urban Culture and Urban Modernization Development [J]. Changjiang Forum; 2000 (05): 58-60.

[5] Yu Kongjian. New Trends in the Protection of World Cultural Heritage--Cultural Routes [J].Urban Issues, 2005(4):30-33.

[6] Li Chenglai. Discussion on the Diversity of Urban Architectural Culture [J]. Shanxi Architecture. 2007(02)

[7] He Lilan. Analysis of Urban Landmarks and Urban Cultural Changes [J]. Modern Business Industry. 2011(14)

[8] Wang Zhenhua. On Architectural Culture from Urban Culture [J]. Shanxi Architecture. 2010(11)

[9] Wang Hongcheng. The Spatial Character of Urban Garden Streetscape [J].Chinese Garden, 2000, (2):58-59.

[10] Dai Meiqi. The Function and Development Ideas of Urban Ecological Garden [J]. Hunan Forestry Science and Technology, 2013, (04). 